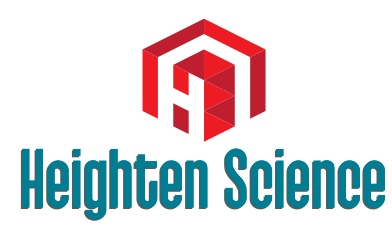

P U B L I C A T I O N S Corporation

\title{
Congenital poisoning after maternal parenteral mercury administration
}

\author{
Benjamin Courchia*, Leventer Roberts Maya, Meyer John, \\ Galvez Maida, Herrera Jaime and Rauch Daniel \\ University of Miami/Holtz Children's Hospital, Miami, FL, USA
}

*Address for Correspondence: Benjamin Courchia, University of Miami/Holtz Children's Hospital, Miami, FL, USA, Email:

benjamin.courchia@jhsmiami.org

Submitted: 04 August 2018

Approved: 29 August 2018

Published: 30 August 2018

Copyright: $\circledast 2018$ Courchia B, et al. This is an open access article distributed under the Creative Commons Attribution License, which permits unrestricted use, distribution, and reproduction in any medium, provided the original work is properly cited

\section{Abstract}

This is the case of a full-term baby girl, born to a mother with a history of parenteral inorganic mercury administration. Thirteen years prior, this mother injected $1 \mathrm{~mL}$ of inorganic mercury in her right forearm, was subsequently hospitalized, but never received chelation treatment. Her first trimester blood and urine mercury concentration were found to be elevated at $28 \mu \mathrm{g} / \mathrm{L}$ (normal $<10 \mu \mathrm{g} / \mathrm{L}$ ) and $162 \mu \mathrm{g} / \mathrm{L}$ (normal $<20 \mu \mathrm{g} / \mathrm{L}$ ) respectively. Her chest $\mathrm{x}$-ray also revealed multiple small punctate metallic densities within the lower lung fields. The remainder of the prenatal course was uneventful. The baby was born at 40 weeks of gestation via uncomplicated caesarian section, and on day of life 3 , blood mercury concentrations were found to be $20 \mu \mathrm{g} / \mathrm{L}$ (normal $<20 \mu \mathrm{g} / \mathrm{L}$ ). The baby, however, remained asymptomatic throughout her hospital stay and on outpatient follow up. She is now two years old. Mercury poisoning in the pediatric population remains a concern, and knowledge of exposure and health effects continues to be relevant as newer uses and modes of exposure are discovered. This case report illustrates a rare perinatal exposure scenario, and, while the mother and child were essentially asymptomatic, the case serves to raise awareness of the many ways in which fetuses, infants, and children may still be exposed to the harmful effects of mercury. This case underscores the need for careful environmental history taking in pregnancy, after birth, and ideally in the pre-conception period as well.

\section{Case Report}

Our patient is a baby girl born at 40 weeks gestation via Caesarian section to a 27 year old woman with previous medical history of mercury poisoning. This baby's mother presented to our institution at 8 weeks of gestation for her first prenatal ultrasound. During the following visit she disclosed a history of substance abuse which included a single use of parenteral mercury thirteen years earlier. Shortly after that episode she was admitted to a local hospital for indeterminate pulmonary and cardiac complications. During that stay no chelating agents were administered and she was subsequently discharged home. She denied any mercury use since that date, and stated that she has maintained a healthy lifestyle. The remainder of her prenatal surveillance was significant for a diagnosis of gestational diabetes mellitus. Two weeks after her initial visit, her blood and urine mercury concentrations were $28 \mu \mathrm{g} / \mathrm{L}$ (normal <10 $\mu \mathrm{g} / \mathrm{L}$ ) and $162 \mu \mathrm{g} / \mathrm{L}$ (normal $<20 \mu \mathrm{g} / \mathrm{L}$ ) respectively. Chest $\mathrm{x}$-ray revealed multiple small punctate metallic densities within the lower lung fields (Figure 1). Considering this mother's distant exposure, her mercury levels were felt to be elevated; thus, possible outcomes of prenatal mercury exposure were explained to the expectant parents, an amniocentesis and chorionic blood sampling were offered but both procedures were declined. At 40 weeks of gestation, the mother underwent caesarian section after failed induction of labor and gave birth to a baby girl. Apgar scores at 1 and 5 minutes were 9 and 9 respectively. The baby's size was appropriate for gestational age with a weight of $2.9 \mathrm{~kg}$, length of $50 \mathrm{~cm}$ and head circumference of $32.5 \mathrm{~cm}$. Newborn physical exam was within normal limits. 


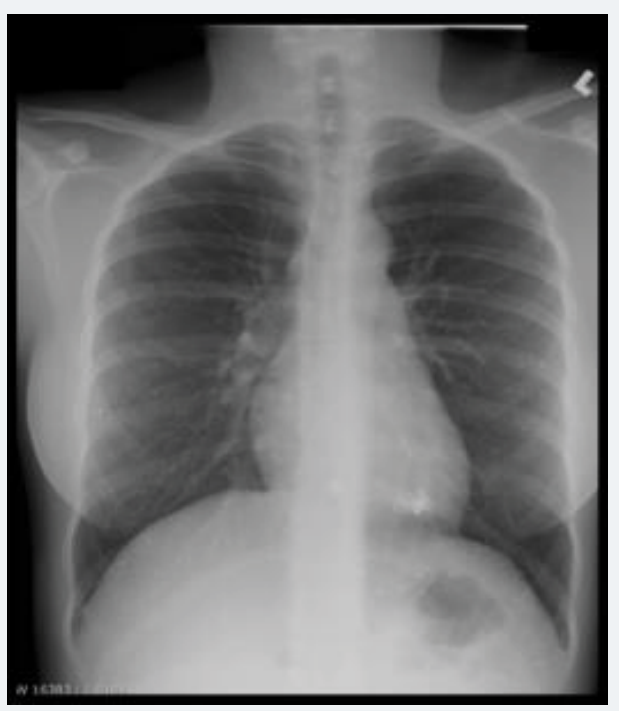

Figure 1: Chest radiograph of the mother showing multiple small punctate metallic densities within the lower lung fields.

The Region II Pediatric Environmental Health Specialty Unit at Mount Sinai Hospital was consulted and recommended obtaining specimens of the newborn's blood, urine and cord blood for mercury concentration level analysis. At day of life 3 , mercury concentrations were found to be $8 \mu \mathrm{g} / \mathrm{L}$ (normal $<10 \mu \mathrm{g} / \mathrm{L}$ ) and $20 \mu \mathrm{g} / \mathrm{L}$ (normal $<20 \mu \mathrm{g} / \mathrm{L}$ ) in urine and blood respectively. The baby's hospital stay remained uneventful. The mother elected to exclusively formula feed the baby and no early signs or symptoms of neurological disturbances were reported. At day of life 8, after the New York City Department of Health declared the child's home environment safe of mercury hazards and the baby was discharged home with detailed safety recommendations given to the parents. The baby was subsequently followed at our outpatient pediatric clinic; at two years of age, her physical exam remains unremarkable, all growth parameters are within normal limits, is neuro-developmentally appropriate for age, and has not displayed any symptoms consistent with mercury poisoning.

\section{Discussion}

Mercury, abbreviated by the letters Hg standing for "hydrargyros" or "water silver" in Greek, is the only metal in liquid form at room temperature. Environmental exposures to mercury occur with the metal in three possible molecular states; elemental or metallic mercury, inorganic compounds (oxides and chlorides of mercury, often used as sterilants and medicinal through the mid- $20^{\text {th }}$ century), and organic compounds (such as methylmercury) that arise from complexing with small organic compounds usually in aqueous environments. Clinical presentation and symptoms of mercury toxicity are closely related to the metal's oxidation state and route of exposure.

Childhood mercury poisoning, first reported in 1903, was observed as early as the late $1^{\text {th }}$ century in Australia. Pink disease, or acrodynia, was initially thought to be a variant of pellagra due to its shared symptomatology. With many patients adequately fed, and with no signs of dietary deficiency, the attention shifted from vitamin deficiency to calomel $(\mathrm{Hg} 2 \mathrm{Cl} 2)$, a mercury-containing teething powder. Incidence of acrodynia dramatically decreased after 1955 , when mercury was removed from teething powders $[1,2]$.

Organic mercury poisoning gained worldwide attention between 1956 and 1970 when several epidemics broke-out around the world. In the 1950's the Chisso chloralkali manufacturing plant dumped mercury effluent in Japan's Minamata bay. Uptake of mercury by algae lead to its conversion to methylmercury, which was then taken up by small aquatic life and bioconcentrated up the food chain into 
larger predator game fish. As a principally fishing community, many of the residents sustained considerable organic mercury exposure though the fish caught in the bay. Both adults and children were affected although perinatal exposures were most severe, as organic mercury crosses both the placenta and the blood-brain barrier with relative ease. Those most severely exposed displayed central nervous system effects including mental retardation, primitive reflexes, cortical blindness, cerebellar ataxia, strabismus, and pyramidal symptoms, as well as disturbances in physical development and nutrition, dysarthria, limb deformity, and hyper-salivation [3,4].

Today, metallic mercury remains a common source of inadvertent mercury exposure in the pediatric population, typically through mercury spills [5]. Medical and scientific equipment, including thermometers and sphygmomanometers are frequent source of mercury spills, especially if they are made out of glass; thankfully these items have been phased out since the 1990's because of such environmental concerns. Mercury spills, particularly at home, tends to attract children because it looks like water silver and can be fun to play with. Poisoning then commonly occurs via inhalation since mercury vaporizes at room temperature, a process augmented by inappropriate use of vacuum cleaners to clean spills. This process agitates and heats the metal increasing the rate of aerosolization. Heavy vapor then settle close to the floor, near the breathing zone of toddlers $[5,6]$. Cutaneous absorption is rarely a concern as elemental mercury does not penetrate the skin unless open cuts are present [7].

Metallic mercury remains in use in dental amalgams, in which it is complexed with other metals including silver or gold; closed-system vapor-barrier traps and other controls are mandatory for dental personnel in the US and Canada who continue to use mercury in dental work. In the developing world, mercury is still used to extract gold from ore and accompanying impurities, this practice remains an important source of poisoning to workers and family members assisting them. Lastly, exposures arising from the use of mercury-containing amulets and charms in the practice of Santería and other traditional Afro-Caribbean religion have been well documented in children who play with, or come into contact with them.

Mercury vapors are absorbed via the lungs and distribute via the bloodstream to organs and soft tissues, including the brain and kidneys. Acute high exposures can present in the form of an acute pneumonitis, with chest pain, dyspnea, and cough, or more rarely, necrotizing bronchiolitis followed by acute respiratory failure. Elemental mercury crosses the blood brain barrier but it may take weeks or even months for neurological symptoms to develop. Neurotoxic manifestations of elemental mercury poisoning are many and varied. Neuropsychiatric disturbances arise from longterm exposures and include headaches, irritability, and depression. A syndrome termed erethism, consisting of a spectrum of symptoms, including agitation, shyness, insomnia, and labile mood has been well described since the $19^{\text {th }}$ century in hatters and other who used mercury in felting animal pelts; this was the origin of the "Mad Hatter," a traditional occupational stereotype made famous by Lewis Carroll in Alice in Wonderland. With regards to nephrotoxicity, mercury may cause damage to both the glomeruli and proximal tubules, with concomitant low molecular weight proteinuria and albuminuria, usually in association with urine mercury levels above $20 \mathrm{mcg} /$ dL. However, mercury may accumulate in the kidneys for up to ten months before translating into abnormal urine levels [8].

Cases of elemental parenteral mercury injection remain quite rare. A literature review between the years 1923 and 2000 revealed only 78 reported cases. A literature search for cases of mercury exposure in utero after intravenous mercury administration did not yield any results making this case truly unique. In an effort to reconcile our patient's worrisome presentation and reassuring outcome, it is necessary to understand the relationship between the oxidation states of mercury 
and their individual ability to cross the placenta. Sequestration in the pulmonary tissues, through formation of granulomata or other tissue reaction has been proposed as a mechanism for similar findings of low mercury blood levels after similar cases of mercury injection [9]. Elemental mercury $\left(\mathrm{Hg}^{0}\right)$ is also slowly oxidized to divalent mercury via an endogenous catalase present in the blood [10,11]. While methylmercury and elemental mercury $\left(\mathrm{Hg}^{0}\right)$ readily cross the placental barrier [12], divalent mercury $\left(\mathrm{Hg}^{++}\right)$usually trapped in maternal blood and organs [13-15], except when found in high concentrations [16].

Possibly, the extended interval between the intravenous administration of mercury and this pregnancy allowed the conversion of mercury into its divalent form, which is less likely to cross the placenta. The additional presence of catalase in the fetal liver, which allows for rapid conversion of circulating $\mathrm{Hg}^{0}$ to $\mathrm{Hg}^{++}[13,16,17]$, may possibly have protected the infant from developmental and neurological complications of transplacental elemental mercury exposure. Developmental follow up remains critical for this patient, especially since neurodevelopmental delay may manifest after months or even years.

The clinician is unlikely to be faced with an exposure scenario as unusual and striking as the one presented here. However, it is useful to be reminded of the numerous ways in which smaller environmental mercury exposures can occur, and that many more individuals may sustain these lower exposures than may be subject to a much more massive single dose. When counseling families on risks of mercury exposure, it is important for families to be aware of potential sources of metallic mercury about the house, and their proper disposal.

\section{Key messages for clinicians to share with families}

In the event of a spill and unsure of what to do, call 911 or your local department of health.

A broken mercury thermometer is a small spill and can typically be handled by homeowner. Pick up the metallic mercury with tape and place in sealed mason jar, then dispose of appropriately as per your local department of health.

Ventilate the home by opening windows.

Do not vacuum as this will increase exposure to mercury vapors.

Pregnant women and children should not be involved in cleanup and should stay away from the area during clean up.

Any spill large than a thermometer should be handled by professionals.

\section{Resources}

\section{Centers for Disease Control and Prevention}

http://www.cdc.gov/biomonitoring/Mercury_FactSheet.html

\section{Agency for Toxic Substances and Disease Registry}

http://www.atsdr.cdc.gov/toxfaqs/tfacts46_metallic_mercury.pdf

\section{Environmental Protection Agency}

http://www.epa.gov/hg/about.htm

http://www.epa.gov/hg/mgmt_options.html

\section{Mount Sinai Environmental and Occupational Health Center}

https://www.mountsinai.org/static_files/MSMC/Files/Patient\%20Care/

Occupational\%20Health/ElementalMercuryExposureIncident.pdf 


\section{American College of Obstetrics and Gynecology}

https://www.acog.org/ /media/Departments/Health\%20Care\%20for\%20 Underserved\%20Women/Images/EnvironmentalChemicalsInfographic.jpg

https://www.acog.org/Resources_And_Publications/Committee_Opinions/ Committee_on_Health_Care_for_Underserved_Women/Exposure_to_Toxic_ Environmental_Agents

http://prhe.ucsf.edu/prhe/index.html

To speak with an expert about environmental exposures affecting children and pregnant or nursing women

\section{National Network of Pediatric Environmental Health Specialty Units}

http://www.aoec.org/pehsu/index.html

\section{Mother to Baby}

https://www.mothertobaby.org/

\section{References}

1. Dally A. The rise and fall of pink disease. Soc Hist Med. 1997; 10: 291-304. Ref.: https://tinyurl.com/y9mndf7z

2. Warkany J, Hubbard DM. Acrodynia and mercury. Journal of Pediatrics gastroenterology. 1953; 42: 365-386. Ref.: https://tinyurl.com/y9b8scjk

3. Harada M. Minamata Disease: methylmercury poisoning in Japan caused by environmental pollution Crit Rev Toxicol. 1995; 25: 1-24. Ref.: https://tinyurl.com/yaj9wosh

4. Harada, M., Congenital Minamata disease. Intrauterine methylmercury poisoning, Teratology 1977 18, 285-288. Ref.: https://tinyurl.com/ybs22m55

5. Baughman TA. Elemental mercury spills. Environ Health Perspect. 2006; 114: 147-152. Ref.: https://tinyurl.com/y9uvjpoy

6. Aguado S, de Quiros IF, Marin R, E. Gago E. Gómez, et al. Acute mercury vapour intoxication: report of six cases. Nephrol Dial Transplant. 1989; 4:133-136. Ref.: https://tinyurl.com/ybxzmzsa

7. Hursh JB, Clarkson TW, Miles EF, Lowell AG. Percutaneous absorption of mercury vapor by man. Arch Environ Health 1989; 44: 120-127. Ref.: https://tinyurl.com/y8q8wmdu

8. Rice $\mathrm{K}$, EM Walker Jr, Miaozong Wu, Chris Gillette, Eric RB. Environmental Mercury and Its Toxic Effects. J Prev Med Public Health. 2014; 47: 74-83. Ref.: https://tinyurl.com/y7ls3nz7

9. Ambre JJ, Michael J, Welshcarl W, Svare. Intravenous elemental mercury injection: blood levels and excretion of mercury. Ann Intern Med. 1977; 87: 451-453. Ref.: https://tinyurl.com/ybm3xjb9

10. Jonsson F, Gunilla SE, Gunnar J. A compartmental model for the kinetics of mercury vapor in humans. Toxicol Appl Pharmacol 1999; 155: 161-168. Ref.: https://tinyurl.com/y7b5p6wl

11. Dencker L. Deposition of metals in embryo and fetus. In: Clarkson T, editor. Reproductive and developmental toxicity of metals. New York: Plenum Press. 1983. 607-637.

12. Al-Saleh I, Neptune S, Abdullah M, Gamal El Din Mohamed, Abdullah R. Heavy metals (lead, cadmium and mercury) in maternal, cord blood and placenta of healthy women. Int J Hyg Environ Health. 2011 214: 79-101. Ref.: https://tinyurl.com/y9cotsar

13. Clarkson TW. The toxicology of mercury. Crit Rev Clin Lab Sci. 1997; 34: 369-403. Ref.: https://tinyurl.com/yd7wuxyo

14. WHO. Methylmercury. Environmental Health Criteria 101, Geneva: World Health Organization. 1990.

15. US Environmental Protection Agency. Mercury study report to congress. An assessment of exposure to mercury in the United States. 1997.

16. Ask K, Akesson A, Berglund M, Marie V. Inorganic mercury and methylmercury in placentas of Swedish women. Environ Health Perspect. 2002; 110: 523-526. Ref.: https://tinyurl.com/ya7h2u8y

17. Aschner M, FL Lorscheider, KS Cowana, DR Conklina, MJ Vimy, et al. Metallothionein induction in fetal rat brain and neonatal primary astrocyte cultures by in utero exposure to elemental mercury vapor (Hg0). Brain Res 1997; 778: 222-232. Ref.: https://tinyurl.com/yaxm5tfq 